\title{
РАЗМЫШЛЕНИЯ О ГРАММАТИКЕ В ОБУЧЕНИИ ИНОСТРАННЫМ ЯЗЫКАМ
}

\author{
REFLECTIONS ON GRAMMAR IN FOREIGN LANGUAGE TEACHING
}

\author{
СТАНИСЛАВ ЙЕЛИНЕК
}

\begin{abstract}
The article describes some changes in views on the role and acquisition of grammar as a set of forms and syntactic structures and as a system of rules and paradigms in foreign language teaching and learning.

An essential part of the article is devoted to explaining key phases that are used when teaching and learning Russian grammar, mainly by presenting various exercises and focusing on the function of forms and structures in communication. This process is presented based on the example of a textbook for Czech learners of the contemporary Russian language.
\end{abstract}

Stanislav Jelínek, Univerzita Karlova - Pedagogická fakulta, Praha - Czechy.

1.

История обучения иностранным языкам свидетельствует о том, что подход к грамматике является одной из самых спорных („вечных”) проблем. Как известно, о грамматике, ее роли в процессе обучения иностранным языкам и о способах ее усвоения выражались и до сих пор выражаются разные, а иногда даже противоположные мнения.

В 1967 году П.Б. Гурвич писал о меняющемся подходе к общим проблемам обучения иностранным языкам, указывая, что

[...] история методики первого периода - это в основном история сменяющих друг друга однобоких учений, смена крайностей, что задача второго, зрелого периода в развитии методики преподавания иностранных языков - это создание системы обучения иностранным языкам, построенной на объективном научно-обоснованном синтезе, [...] что возникло стремление сочетать в учебном процессе такие элементы, которые раньше рассматривались как исключающие друг друга, [...] что основным стал вопрос об условиях и границах применения какого-то способа обучения или вида упражнения, [...] что периоду борьбы крайностей сегодня должен прийти на смену [...] подлинно научный синтез ${ }^{1}$.

1 П.Б. Г у р в и ч, К вопросу о специффике методики преподавания иностранных языков как науки, „Иностранные языки в школе” 1967, № 3, с. 24-30. 
Приведенные мысли, по нашему мнению, можно понимать и в отношении к обучению грамматике.

Разные мнения о грамматике в процессе обучения иностранным языкам выражались и тогда, когда уже доминировала идея о коммуникативной направленности преподавания иностранных языков:

There are differing views on the role of explicit grammar instruction in a communicative approach. Some coursewriters and syllabus designers prefer a sound structural base on which to build communication skills. Others stress the importance of fluency activities and assume that grammatical competence will look after itself whether or not there is explicit grammar teaching. Between these two poles there are a variety of approaches $[\ldots]^{2}$.

Если в начале развития коммуникативно-направленного обучения иностранным языкам роль грамматических правил явно минимализировалась, то позднее вопросы, касающиеся грамматики, стали опять привлекать внимание теоретиков и практиков:

Communicative methods led to a more or less total abandonment of grammatical analysis and formal learning of rules. Today, theorists and practitioners are asking more finely shaded and doubtlessly more pertinent questions ${ }^{3}$.

Как отметила I. Pýchová,

although the present advocates of the Communicative Approach deny the neglect of grammar [...], there were instances of authors who asked teachers to concentrate on problems of vocabulary [...] on the grounds that grammar will look after itself. $[\ldots]$ The problem of grammar, newertheless, has always been a thorny one ${ }^{4}$.

Упрощая, можно сказать, что преобладающий в последнее время подход к проблемам обучения грамматике иностранных языков характеризуется более или менее выразительным стремлением к постепенному преодолению крайностей и односторонних концепций, переоценивавших или, наоборот, недоценивавших роль грамматики в преподавании иностранных языков. Например, А.В. Величко в своей статье о современном учебнике русского языка как иностранного пишет, что „грамматика на данном этапе играет очень важную роль, но роль средства для достижения цели, а не самой цели" ${ }^{\prime \prime}$. Как отмечает М.Л. Вайсбурд,

2 J. S h e i 1 s, Communication in the Modern Language Classroom, Project 12. "Learning and Teaching Modern Languages for Communication. Council of Europe Press" 1991, c. 259.

${ }^{3}$ Learning Modern Languages at School in the European Union, Education Training Youth. Studies 6. European Commission, Luxembourg 1997, c. 16.

4 I. P ý c h o v á, The Communicative Approach Revisited, [в:] XXI. ročenka Kruhu moderních filologi̊, Praha 1997, c. 139.

${ }^{5}$ А.В. В е л и ч к о, Регламентация проиесса обучения и современный учебник РКИ, „Русский язык за рубежом” 2005, № 3-4, с. 34. 
отношение к грамматике - очень важный фактор в любом методическом подходе [...]. Однако, опора на грамматику [...] приобретает различные формы и содержание в зависимости от особенностей используемого материала, его сложности, соотношения с аналогом в родном языке. [...] Учитель имеет право на выбор. Хотя правильнее было бы говорить не о выборе, а о разумном сочетании используемых подходов, которые не столько противоречат друг другу, сколько взаимодополняют друг друга 6 .

M. Celce-Murcia, опираясь на характеристику четырех разных подходов к обучению иностранным языкам, формулирует интересное заключение:

These four more recent approaches are not necessarily in conflict or totally incompatibille since it is not impossible to conceive of an integrated approach which would include attention to rule formation, affect, comprehension and communication [...]. In fact, many teachers would find such an approach, if well conceived and well integrated, to be very attractive ${ }^{7}$.

\section{2.}

Недоразумения и неясности, касающиеся грамматики в процессе обучения иностранному языку, нередко вытекали (и, может быть, еще до сих пор вытекают) из неоднозначного понимания и употребления слова „грамматика". Поэтому необходимо точнее различать два значения этого слова: грамматику как грамматический строй языка (как репертуар словоформ и синтаксических структур) и грамматику как лингвистическую дисциплину - как теорию, как систему грамматических правил и парадигм 8 .

В необходимости усвоения грамматического строя языка (репертуара словоформ и синтаксических структур) нет сомнений, так как без владения этими грамматическими средствами нельзя осуществить полноценную коммуникацию. Овладение грамматическим строем языка и его функциональным использованием в соотношении с лексикой, с фонетическими и графическими средствами является необходимым условием для выполнения коммуникативной цели обучения языку.

До сих пор не совсем ясным является вопрос о том, какую роль может играть в обучении иностранным языкам грамматика, понимаемая как теория - как система правил и парадигм.

${ }^{6}$ М.Л. В а й с б у р д, Методы обучения. Выбор за вами, „Иностранные языки в школе" 2000, № 2, с. 32, 34 .

${ }^{7}$ M. C e 1 c e - M u r c i a, Language Teaching Approaches: An Overview, [в:] Teaching English as a Second or Foreign Language, Second Edition, Boston 1991, c. 89.

8 A.V. I s a č e n k o, Die russische Sprache der Gegenwart. Teil I: Formenlehre, Halle (Saale) 1962, c. 3. 
Учитывая цели и условия обучения русскому языку и другим иностранным языкам в школах Чешской Республики, можно констатировать, что овладение обоснованно отобранными правилами и парадигмами может и должно служить средством для практического усвоения словоформ и синтаксических структур.

Необходимо еще добавить, что роль правил и парадигм в процессе обучения иностранному языку следует понимать в динамическом смысле, так как целесообразность их отбора, дозировки, способов презентации и фиксации зависит от ряда факторов (от целей курса или класса, от возраста и языковой подготовленности учащихся, от уровня их абстрактного мышления, от стадии обучения языку и т.д.).

Одним из факторов, от которых зависит отбор и способ оформления грамматических правил и парадигм, является, несомненно, прогнозирование и учет межъязыковой и внутриязыковой интерференции, имеющей, как известно, ряд особенностей при обучении русскому языку в условиях близкородственной инославянской среды.

Уже давно известно, что в некоторых случаях, например, при обучении русскому языку младших школьников, рекомендуется использовать лексическое объяснение и закрепление словоформ, словосочетаний или даже целых предложений, то есть их введение без обобщающих правил. Лексическое усвоение грамматических явлений может служить предварительной подготовкой учащихся к последующему обобщению знаний и их системному представлению в правилах и парадигмах. В таких случаях речь идет, как известно, о т. наз. лексической антиципации.

\section{3.}

В процессе обучения русскому языку как иностранному можно считать эффективным такой подход, при котором новые для учащихся грамматические явления вводятся в связном тексте, демонстрирующем функциональное использование словоформ и синтаксических структур в соотношении с соответствующей лексикой. Как отметила О.Д. Митрофанова,

[...] осмысление учебного материала практически начинается с текста, который является материалом для наблюдения определенных слов и структур, он иллюстрирует семантику изучаемых единиц разных уровней, их сочетания с другими единицами в речи. В связи с этим учебный текст возможно считать одним из компонентов системы упражнений 9

${ }_{9}^{9}$ О.Д. М и т р о ф а н о в а, О методических и психологических требованиях к системе упражнений по русскому языку, [в:] Русский язык для студентов-иностраниев 12, Москва 1972, с. 6. 
В следующей части наших размышлений приводим общую характеристику презентации и фиксации грамматического материала в учебнике (в учебно-методическом комплексе), предназначенном для обучения русскому языку в средних школах Чешской Республики ${ }^{10}$.

После вводного текста, помещенного в начале каждого тематического раздела учебника, следуют опирающиеся на вводный текст лексические, а потом грамматические упражнения. Важную роль играет отбор и обоснованная преемственность упражнений, направленных на отдельные дозы грамматического материала и, в связи с этим, на предотвращение межъязыковой и внутриязыковой интерференции. Надо подчеркнуть, что взаимосвязанные упражнения, упорядоченные в блоках и секвенциях, создают благоприятные условия для реализации коммуникативно-деятельностного подхода к усвоению словоформ и синтаксических структур $\mathrm{p}^{11}$ и, в связи с этим, постепенно подводят учащихся к формулировке элементарных обобщений в правилах и парадигмах. Следовательно, с грамматическим материалом, который вводится небольшими дозами - квантами ${ }^{12}$, учащиеся знакомятся в действии, преимущественно индуктивным путем, сначала на конкретном уровне в устной и в письменной форме, а потом и на уровне абстракции и обобщения. Как написала W. Rivers, „At whatever stage a new structure is introduced, it should be presented first in concrete form in speech or writing, before it becomes the object of an abstract organisation"13.

Следующие блоки упражнений направлены на практическое использование правил и парадигм и, на этой основе, на последовательное развитие грамматических умений, которые постепенно автоматизируются и становятся компонентами комплексной речевой деятельности.

Для ее целенаправленного развития служат блоки заданий речевого типа, максимально приближенные к реальной, то есть неучебной, свободной коммуникации, характеризующейся преобладающей концентрацией внимания участников не на грамматике или на других языковых средствах, а на содержании высказывания.

10 S. J e 1 í n e k, L.F. A l e x e j e v a, R. H ř íb k o vá, H. Ž of k o vá, Padyza no-Hoвому 1, 2, 3, 4, 5 (učebnice, pracovni sešit, príručka učitele, audionahrávka k učebnici), Nakladatelství Fraus, Plzeň 2007, 2008, 2009, 2010, 2011.

11 W. W o ź n i e w i c z, Kierowanie procesem glottodydaktycznym, Warszawa 1987, с. 217-262; Р.П. М и л ь р у д, И.Р. М а к с и м о в а, Современные кониептуальные принцииы коммуникативного обучения иностранным языкам, „Иностранные языки в школе" 2000, № 4, с. 9-15.

12 Е.И. П а с с о в, Основы методики обучения иностранным языкам, Москва 1977, c. 152.

13 W.M. R i v e r s, Teaching Foreign-Language Skills, Chicago-London (1968), 1970, c. 84. 
В намеченной концепции заложены предпосылки для обоснованного использования взаимоотношений между текстом и последовательностью упражнений, между грамматикой и лексикой, между системностью и коммуникативностью ${ }^{14}$.

Вышеописанный подход к грамматике, который реализуется в процитированном учебно-методическом комплексе русского языка для средних школ ЧР, представляет собой проверенный практикой проект, позволяющий преподавателю гибко приспосабливать намеченные учебником способы обучения к меняющимся ситуациям учебного процесса. Конкретные возможности, примеры и варианты такого приспособления приводятся в книге для учителя, являющейся одним из компонентов вышеназванного учебно-методического комплекса. Его элекронический вариант позволяет непосредственно реагировать на индивидуальные потребности учащихся, повышать и развивать их мотивацию и активность.

В заключение следует отметить, что к тематике статьи прямо или косвенно относятся концептуально ценные теории, описанные в публикациях, авторами которых являются И.Ф. Комков и В.П. Круглова, R. Batstone, D. Larsen-Freeman, J.O. Hruška, L. Ries ${ }^{15}$.

14 В. Б е с п а л е н к о, Интеграциия принцииоо коммуникативности и системности В практическом овладении языком, [в:] $V$ Международный конгресс преподавателей русского языка и итературы. Тезисы докладов и сообщений, Прага 1982, с. 206; М.Н. В я т ю т н е в, Теория учебника русского языка как иностранного, Москва 1984, с. 123.

15 И.Ф. К о м к о в, В.П. К р у г л о в а, Уровни абстракции активного (коммуникативного) метода, [в:] Проблемы активного метода обучения иностранным языкам, Минск 1970, с. 3-14; R. В a t s t о n e, Grammar, 0xford-New York (1994), 2003, с. 3-147; D. L a r s e n - F r e e m a n, Teaching Grammar, [в:] Teaching English as a Second or Foreign Language, Second Edition, Boston 1991, c. 277-296; J.O. H r u š k a, Metodologie jazyka francouzského, Praha 1926; L. R i e s, Didaktika ruštiny 1, 2, PF Ostrava 1987. 